\title{
Kinetic Modeling of Light Limitation and Sulfur Deprivation Effects in the Induction of Hydrogen Production With Chlamydomonas reinhardtii. Part II: Definition of Model-Based Protocols and Experimental Validation
}

\author{
B. Degrenne, J. Pruvost, M. Titica, H. Takache, J. Legrand \\ Université de Nantes, CNRS, GEPEA UMR-CNRS 6144, Bd de l'Université, CRTT-BP 406, \\ 44602 Saint-Nazaire Cedex, France; telephone: +33-2-40-17-26-68; fax: +33-2-40-17-26-18; \\ e-mail: jeremy.pruvost@univ-nantes.fr
}

\begin{abstract}
Photosynthetic hydrogen production under light by the green microalga Chlamydomonas reinhardtii was investigated in a torus-shaped PBR in sulfur-deprived conditions. Culture conditions, represented by the dry biomass concentration of the inoculum, sulfate concentration, and incident photon flux density (PFD), were optimized based on a previously published model (Fouchard et al., 2009. Biotechnol Bioeng 102:232-245). This allowed a strictly autotrophic production, whereas the sulfur-deprived protocol is usually applied in photoheterotrophic conditions. Experimental results combined with additional information from kinetic simulations emphasize effects of sulfur deprivation and light attenuation in the PBR in inducing anoxia and hydrogen production. A broad range of PFD was tested (up to $500 \mu \mathrm{mol}$ photons $\mathrm{m}^{-2} \mathrm{~s}^{-1}$ ). Maximum hydrogen productivities were $1.0 \pm 0.2 \mathrm{~mL} \mathrm{H}_{2} / \mathrm{h} / \mathrm{L}$ (or $25 \pm 5 \mathrm{~mL}$ $\mathrm{H}_{2} / \mathrm{m}^{2} \mathrm{~h}$ ) and $3.1 \mathrm{~mL} \pm 0.4 \mathrm{H}_{2} / \mathrm{hL}$ (or $77.5 \pm 10 \mathrm{~mL} \mathrm{H}_{2} /$ $\mathrm{m}^{2} \mathrm{~h}$ ), at 110 and $500 \mu \mathrm{mol}$ photons $\mathrm{m}^{-2} \mathrm{~s}^{-1}$, respectively. These values approached a maximum specific productivity of approximately $1.9 \mathrm{~mL} \pm 0.4 \mathrm{H}_{2} / \mathrm{h} / \mathrm{g}$ of biomass dry weight, clearly indicative of a limitation in cell capacity to produce hydrogen. The efficiency of the process and further optimizations are discussed.
\end{abstract}

KEYWORDS: hydrogen; Chlamydomonas reinhardtii; modeling; experimental validation; autotrophy; PBR; sulfur deprivation

\section{Introduction}

Hydrogen is a primary energy vector through its combustion or dissociation, leading to energy production with a release of water molecules. Photosynthetic microorganisms can produce hydrogen gas using mainly light and water, and are the most plentiful natural resources on Earth. They have therefore attracted interest (Gaffron and Rubin, 1942; Ghirardi et al., 2000). In the green microalga Chlamydomonas reinhardtii, hydrogen production is catalyzed by an [Fe]-hydrogenase that has a strong enzymatic activity, but which is strongly inhibited by oxygen (Benemann et al., 1973; Ghirardi et al., 1997, 2000). As light supply is required to sustain hydrogen production, overcoming this limitation is difficult, because the algae produce photosynthetic oxygen in light. Melis et al. (2000) and Zhang et al. (2002) have shown that inorganic sulfate deprivation of a $C$. reinhardtii suspension causes a time separation between release of oxygen and production of hydrogen gas under light. This metabolic switch was explained by the progressive, reversible inactivation of the photosynthetic capacities, which in about $48 \mathrm{~h}$ induced an oxygen production below its consumption by mitochondrial respiration, leading to anoxic conditions and $\mathrm{H}_{2}$ release. In addition, sulfur deprivation was found to induce starch accumulation in algae, which in turn enhanced $\mathrm{H}_{2}$ release (the PSII-independent pathway; see Fouchard et al., 2009). All these effects observed during the sulfur deprivation protocol led to a sustainable hydrogen production rate, with around $3.5 \mathrm{~mL} / \mathrm{h} / \mathrm{L}$ obtained in a Roux bottle $5 \mathrm{~cm}$ thick. Further work has been done since these preliminary studies, but hydrogen production using green algae is currently still low (a few $\mathrm{mL} / \mathrm{h} / \mathrm{L}$ of culture). A systematic optimization on both the biological and the process sides remains necessary. As shown in numerous studies (see Fouchard et al., 2009 for a detailed review), biological responses and environmental conditions prevailing in the culture vessel, that is, one or more photobioreactors (PBRs), are closely related. 
The sulfur-deprived protocol has been widely investigated and practical processes for photobiological hydrogen production developed. For example, the effect of re-addition of inorganic sulfur in the culture medium was investigated (Kosourov et al., 2002, 2005), enabling cycles of hydrogen gas production (Ghirardi et al., 2000; Guo et al., 2008; Kim et al., 2010; Melis, 2002). A $0.4 \mathrm{mM}$ inorganic sulfur solution was injected after a $60 \mathrm{~h}$ hydrogen production phase, reactivating $\mathrm{PS}_{\mathrm{II}}$ and causing an accumulation of starch with net oxygen release. After the sulfur consumption by cells for their growth, anaerobic conditions were again reached and a new hydrogen gas production cycle began. Three to five full hydrogen gas production cycles were obtained.

The possibility of producing hydrogen gas over a long period of time is also of great interest. Fedorov et al. (2005) demonstrated the possibility of producing sustainable hydrogen gas for a period of at least $4,000 \mathrm{~h}$. The authors used two PBRs for the different phases of the process. In the first PBR, cells were cultivated in chemostat mode in limiting sulfur conditions to accumulate starch. Cells were then injected in a second PBR where the residual sulfur concentration was consumed to reach anaerobic conditions and then produce hydrogen under light.

Laurinavichene et al. (2006) have shown that higher hydrogen production rates could be achieved (also shown by Laurinavichene et al., 2002) by fixing cells on a glass fiber matrix. This allowed easy switching from a classical growth medium to a sulfur-deprived medium that then induced the anaerobic phase. A hydrogen gas production phase was sustained for 4 weeks with an average rate of $45 \mathrm{~mL} \mathrm{H}_{2}$ /day/ mg chl. This result was $2 / 3$ lower than in cell suspension, as obtained by Melis (2002). A further optimization was more recently proposed by Laurinavichene et al. (2008), who injected a limiting sulfur concentration in the medium. This enabled cycles of hydrogen production to be obtained in the same PBR. The $\mathrm{H}_{2}$ production was observed for up to 90 days.

Despite all these efforts to optimize the sulfur-deprived protocol, hydrogen production rates remain low (the energy yield of the light-to-hydrogen conversion is around 0.1$0.2 \%$, with an expected ceiling of $10 \%$; see Fouchard et al., 2009). Another severe limitation is in the use of acetate in the medium, usually included in several studies (mixotrophic conditions). At the process level, this increases bacterial contamination risk and, more seriously, leads to non-negligible carbon dioxide production (Degrenne et al., 2010a), which is incompatible with the aim of a "clean" hydrogen production with no greenhouse gas release. The elimination of acetate from the medium is thus a major concern. Fouchard et al. (2005) used dissolved carbon dioxide as the sole carbon source (strictly autotrophic conditions) and showed that starch could also be accumulated in sulfur-deprived conditions. The main difference was in the amount of starch accumulated, which was half as much in autotrophic than in mixotrophic conditions. A lower hydrogen production rate was observed. However, acetate addition to the medium does not only affect starch accumulation. Mixotrophic conditions also facilitate the establishment of anoxic conditions. In Fouchard et al. (2005), studies were conducted in autotrophic conditions and a $\mathrm{PS}_{\mathrm{II}}$ inhibitor (DCMU) was added to prevent oxygen release. However, such a solution cannot be reasonably envisaged at a large scale.

Tsygankov et al. (2006) proposed a method for obtaining and maintaining anoxia for a hydrogen production phase in strictly autotrophic conditions, by using different specific incident photon flux densities (PFDs) during the sulfur-deprived and hydrogen production phases (120 and $25 \mu \mathrm{mol}$ photons $\mathrm{m}^{-2} \mathrm{~s}^{-1}$, respectively). The principle of regulating oxygen release by the control of PFD was introduced here. This protocol was recently extended by presenting the theoretical framework necessary to adapt the PFD for hydrogen production as a function of the PBR geometry and biomass optical properties (pigmentation) and concentration, to take into account light transfer conditions in the PBR and its effect on the oxygen production due to photosynthetic activity. A rigorous control of radiative transfer conditions in particular allowed hydrogen production without sulfur deprivation (Degrenne et al., 2010b). Despite this apparent progress, a comparison of hydrogen production rate under different growth conditions (Kosourov et al., 2007) revealed that hydrogen production rate in autotrophic conditions was at least four times lower than in mixotrophic conditions.

Whatever the protocol of hydrogen production with algae, a strong coupling is emphasized between environmental conditions (PFD, sulfur concentrations) and biological responses (photosynthetic activity, oxygen and hydrogen production). Modeling interactions between physical and biological phenomena can thus be useful for setting up and optimizing $\mathrm{H}_{2}$-producing strategies at the PBR level. For this purpose, kinetic modeling of the induction of anaerobic conditions has been proposed by Fouchard et al. (2009). The resulting model describes the kinetics of extra- and intracellular sulfur, total biomass, and intracellular starch concentrations as a function of environmental conditions. It was shown that the model was able to describe different phenomena induced by sulfur deprivation and leading to $\mathrm{H}_{2}$-producing conditions. The model has been thoroughly described, together with the model parameter identification procedure. Our purpose here was to validate this model in a laboratory-scale torusshaped PBR. Using the theoretical framework provided here in the case of a sulfur-deprivation protocol, a global optimization was conducted. The aim was to reconcile autotrophic conditions and a maximized $\mathrm{H}_{2}$ production in a single PBR. As demonstrated, a proper definition of the PFD and initial sulfur concentration assists the different steps in achieving hydrogen production, namely biomass growth, progressive sulfur consumption, establishment of anoxic conditions, and finally hydrogen release at high volumetric rates. 


\section{Materials and Methods}

\section{Strain, Culture Medium, Cultivation Conditions}

Wild-type C. reinhardtii strain 137AH was taken from a culture collection belonging to the CEA (Cadarache, France). Microalgae were incubated in conical flasks placed in an incubator at $25^{\circ} \mathrm{C}$ under approximately $100 \mu$ mol photons $\mathrm{m}^{-2} \mathrm{~s}^{-1}$ in standard TAP medium (New Brunswick Innova ${ }^{\circledR} 44$ incubator). Cultures were replicated every 2 weeks. When the biomass concentration had reached about $10^{6} \mathrm{cell} / \mathrm{mL}$, the cells were centrifuged $\left(2,000 \mathrm{rpm}, 5 \mathrm{~min}\right.$, and $\left.20^{\circ} \mathrm{C}\right)$ and the pellet was suspended in fresh new medium. The medium and the algae were then transferred to the torus-shaped PBR for investigation. Fresh new medium was based on minimum medium for growth (MMG, see Harris, 1989 for further details). Nutrient concentrations were adapted to prevent any mineral starvation, except for sulfur when required. The medium composition was (in g/L of culture): $\mathrm{NaHCO}_{3} 1.68, \mathrm{NH}_{4} \mathrm{Cl}$ 1.45, $\mathrm{KH}_{2} \mathrm{PO}_{4} 0.61, \mathrm{CaCl}_{2}, 2 \mathrm{H}_{2} \mathrm{O}$ 0.05, Hutner solution $1 \mathrm{~mL} / \mathrm{L}$. The initial sulfate concentration was adjusted by adding the appropriate amount of $\mathrm{MgSO}_{4} \cdot 7 \mathrm{H}_{2} \mathrm{O}$ (see text). Data are given in $\mathrm{mg}$ of sulfate $\left(\mathrm{SO}_{4}^{2-}\right)$ per liter.

\section{Analytical Methods}

Biomass concentration $X$ was determined by sampling a volume $V$ of culture directly from the PBR through a septum. A filter (Whatman GF/F), previously oven-dried at $110^{\circ} \mathrm{C}$ for $24 \mathrm{~h}$, was weighed and then used to filter the volume sample. After briefly rinsing with de-ionized water, the filter was oven-dried at $110^{\circ} \mathrm{C}$ for $24 \mathrm{~h}$ and reweighed. The filter mass difference divided by the sample volume gave the biomass concentration $X$ in $\mathrm{kg} \mathrm{m}^{-3}$.

Starch was assayed with a commercial kit (Sigma-Aldrich, France, Starch (HK) Assay kit SA20) after purification by the method of Klein and Betz (1978). The method is described in Fouchard et al. (2005).

Sulfate concentration in the medium was measured using anionic chromatography (DIONEX-120, IonPac AS12A anionic column). The eluant was a solution of $270 \mathrm{mM}$ $\mathrm{Na}_{2} \mathrm{CO}_{3}$ and $30 \mathrm{mM} \mathrm{NaHCO}$ with a flow rate of $1.5 \mathrm{~mL} /$ min.

The volumetric illuminated fraction $\gamma$ (characterizing light conditions in a PBR) is given by the depth of culture where the irradiance of compensation point $G_{c}$ is obtained (see Degrenne et al., 2010 or Takache et al., 2010 for details):

$$
\gamma=\frac{z_{\mathrm{c}}}{L}
$$

where $z_{\mathrm{c}}$ is the compensation point in the depth of culture, defined by $G\left(z_{\mathrm{c}}\right)=G_{\mathrm{c}}$. $G_{\mathrm{c}}$ was assigned a value of about $10 \pm 3 \mu \mathrm{mol}$ photons $\mathrm{m}^{-2} \mathrm{~s}^{-1}$ for the green microalga C. reinhardtii (Takache et al., 2010).

\section{PBR Description}

All the cultures were conducted in a torus-shaped PBR. This PBR was already described in previous work (Fouchard et al., 2008) and had a specific illuminated surface of $25 \mathrm{~m}^{-1}$ (light path $0.04 \mathrm{~m}$, illuminated surface $0.0317 \mathrm{~m}^{2}$ ). The light source was changed to an array of white LEDs, allowing easier control of the PFD (Degrenne et al., 2011). Oxygen, carbon dioxide, and hydrogen concentrations in the output gaseous phase were measured with a mass spectrometer (Pfeiffer Vacuum, QMS 200). A mass flowmeter (Bronkhörst, France, Montigny-Les-Cormeilles) was used to determine the gas flow rate at the PBR output. In this way, $\mathrm{O}_{2}, \mathrm{CO}_{2}, \mathrm{~N}_{2}$, and $\mathrm{H}_{2}$ production rates were monitored online. The $\mathrm{pH}$ was measured online (Mettler Toledo Inpro $3253 S G / 120 /$ Pt100 probe) and set to 7.5 by addition of pure $\mathrm{CO}_{2}$. A minimum interval of $3 \mathrm{~h}$ between two $\mathrm{CO}_{2}$ injections was set so as to obtain gas-liquid equilibrium in the PBR to facilitate subsequent mass carbon balance determination. As a consequence, $\mathrm{pH}$ was allowed to vary from 7.5 to 8.2 during experiments. The volumetric $\left(\mathrm{mL} \mathrm{H}_{2} / \mathrm{Lh}\right)$ and areal $\left(\mathrm{mL} \mathrm{H}_{2} / \mathrm{m}^{2} \mathrm{~h}\right)$ hydrogen productivities are given to facilitate comparison with other results in the literature.

\section{Modeling and Simulation}

In our previous article (Fouchard et al., 2009), a kinetic model was developed to relate culture evolution from standard photosynthetic growth conditions to $\mathrm{H}_{2}$-producing conditions. Only the main features of the model are given here. It consists of a set of ordinary differential equations (ODEs) obtained from a mass balance conducted on the PBR for the biomass, extracellular and intracellular sulfur, assuming perfectly mixed conditions and thus homogenous concentrations in the cultivation system. Kinetic laws are then introduced by considering the following pseudo-reaction scheme:

$$
S \stackrel{\left\langle r_{\mathrm{S}}\right\rangle}{\longrightarrow} Q \text { and } Q \stackrel{\left\langle r_{x_{\mathrm{p}}}\right\rangle}{\longrightarrow} X
$$

where $X$ is the biomass concentration, $S$ is the extracellular sulfur concentration, and $Q$ is the intracellular concentration expressed here as a quota (ratio of intracellular sulfur concentration to biomass concentration) following the Droop formulation (see Fouchard et al., 2009).

The corresponding ODEs are:

Total biomass concentration $(X): \frac{\mathrm{d} X}{\mathrm{~d} t}=\left\langle r_{X}\right\rangle-D X$

Extracellular sulfur concentration $(S)$ :

$$
\frac{\mathrm{d} S}{\mathrm{~d} t}=-\left\langle r_{\mathrm{S}}\right\rangle+D\left(S_{i}-S\right)
$$

Intracellular sulfur quota $(Q): \frac{\mathrm{d} Q}{\mathrm{~d} t}=\frac{\left\langle r_{\mathrm{S}}\right\rangle-\left\langle r_{X_{\mathrm{p}}}\right\rangle Q}{X}$ 
Starch concentration $\left(X_{\mathrm{c}}\right)$ :

$$
\begin{aligned}
& \frac{\mathrm{d} X_{\mathrm{c}}}{\mathrm{d} t}=0 \quad \text { and } \quad \frac{\mathrm{d} X_{0}}{\mathrm{~d} t}=\frac{\mathrm{d} X}{\mathrm{~d} t} \quad \text { if } \quad S>S_{\lim } \\
& \frac{\mathrm{d} X_{\mathrm{c}}}{\mathrm{d} t}=\frac{\mathrm{d} X}{\mathrm{~d} t} \quad \text { and } \quad \frac{\mathrm{d} X_{0}}{\mathrm{~d} t}=0, \text { if } \quad S<S_{\lim } \\
& \text { with } X=X_{0}+X_{\mathrm{c}}
\end{aligned}
$$

These equations are expressed here for continuous operation of the PBR, with $D$ the dilution rate. Kinetic rates $\left\langle r_{X_{\mathrm{p}}}\right\rangle,\left\langle r_{X}\right\rangle$, and $\left\langle r_{\mathrm{S}}\right\rangle$ are given by:

$$
\text { Photosynthetic rate : }\left\langle r_{X_{\mathrm{p}}}\right\rangle=\left\langle\mu_{\mathrm{G}}\right\rangle f(Q) X
$$

Growth volumetric rate : $\left\langle r_{X}\right\rangle=\left\langle r_{X_{\mathrm{P}}}\right\rangle-\mu_{\mathrm{s}} X$

Extracellular sulfur absorption rate :

$$
\left\langle r_{\mathrm{S}}\right\rangle=Y_{\mathrm{s} / x}\left\langle\mu_{\mathrm{G}}\right\rangle \frac{S}{K_{\mathrm{S}}+S} X
$$

where $\mu_{\mathrm{s}}$ is a kinetic parameter related to the respiration process, described here as a constant maintenance term. $f(Q)$ is a function relating the influence of the interacellular sulfur quota on the photosynthetic activity, expressed as follows:

$$
\begin{gathered}
f(Q)=f_{\min }+\left(1-f_{\min }\right) \frac{\exp \left(k \frac{Q}{Q_{m}}\right)-1}{\exp (k)-1} \\
\text { if } Q<Q_{\mathrm{m}} \text {, else } f(Q)=1
\end{gathered}
$$

with $Q_{m}$ is the maximum quota above which the photosynthetic activity is not affected, $k$ and $f_{\min }$ being fitting constants.

$\left\langle\mu_{\mathrm{G}}\right\rangle$ represents the average photosynthetic growth rate with respect to the light received, calculated over the culture volume by integrating the local photosynthetic response:

$$
\left\langle\mu_{\mathrm{G}}\right\rangle=\frac{1}{L} \int_{0}^{L} \mu_{\max } \frac{G(z) X}{G(z)+K_{\mathrm{I}}+\frac{G(z)^{2}}{K_{\mathrm{II}}}} \mathrm{d} z
$$

where $G(z)$ represents the local value of the irradiance determined using a radiative model (see Part I for details) and $\mu_{\mathrm{max}}, K_{\mathrm{I}}$, and $K_{\mathrm{II}}$ are the kinetic parameters linked to the photosynthetic response to light.

All equations (1-11) previously described were used here without modification, except for Equations (5) and (9), which introduce an on/off switch near $S_{\lim }$ and $Q_{\mathrm{m}}$ threshold values, respectively. This was introduced to represent the change in metabolism when sulfur starvation occurs from classical growth to starch accumulation (Eq. 5) and to define a value of the quota above which the photosynthetic activity was not affected (Eq. 9). For numerical simulation and model-based optimization, continuous formulations are, however, to be preferred. Sigmoid switch functions $f\left(S_{\mathrm{i}}\right)$ were thus introduced. They were multiplied by the kinetic rates on $Q_{c}$ and $f(Q)$, to replace on/off switches near $S_{\lim }$ and $Q_{\mathrm{m}}$ threshold values:

$$
f\left(S_{\mathrm{i}}\right)=\frac{1}{1+\exp \left[-a\left(S_{\mathrm{i}}-S_{\mathrm{i}, t}\right)\right]}
$$

This function switches from 0 to 1 around the threshold value $S_{\mathrm{i}, t}$ and the parameter $a$ defines the steepness of the regulation. The same was applied for the quota $Q$.

Simulations were performed using Matlab 7.7.7(R2008b) (The Mathworks, Inc., Natick, MA). The ODE system was numerically integrated using the "ode15S" routine.

\section{Additional Experiments to Improve Identification of Model Parameters}

The set of model parameters proposed in Part I was obtained from various experiments, not fully representative of the cultivation performed here where high biomass concentrations were achieved. Parameters linked to photosynthetic growth $\left(\mu_{\max }, K_{\mathrm{I}}, K_{\mathrm{II}}\right.$, and $\left.\mu_{\mathrm{s}}\right)$ were determined in low culture concentrations (turbidostat mode). As shown recently (Takache et al., 2010), working in dilute culture can significantly affect PBR operation and biological response, leading to the "kinetic" regime. Dense culture (leading to the "physical limitation by light") has to be privileged to prevent, for example, cell photoinhibition. This important specific feature that occurs when working in a PBR can be illustrated here by comparing simulation results using parameters obtained in low concentration culture with experimental data obtained for conditions leading to $\mathrm{H}_{2}$ production but with a high biomass concentration (a PFD of $110 \mu \mathrm{mol} \mathrm{m}^{-2} \mathrm{~s}^{-1}$ and an initial sulfur concentration of $6 \mathrm{mg} / \mathrm{L})$. This first comparison indicates that the qualitative properties of the model correspond to the experimental observations, but quantitatively, kinetics are badly represented, as illustrated in Figure 1. The maximal biomass concentration was well predicted $\left(\sim 0.6 \mathrm{~kg} \mathrm{~m}^{-3}\right)$, but the batch duration was half as fast as the real one. As a result, starch accumulation was not predicted, though occurring in practice (Fig. 1c). This result suggests that the values of parameters reported in Part I $\left(\mu_{\max }=0.2274 \mathrm{~h}^{-1}\right.$ and $\mu_{\mathrm{s}}=0.032 \mathrm{~h}^{-1}$ ) do not correspond to conditions investigated here, with also a possible evolution of those parameters over the course of batch duration, as the culture evolves progressively from a low (kinetic regime) to high concentration with full light absorption. There is thus an inherent identification problem in estimating a single set of parameters for a broad domain of experimental conditions.

A global re-identification procedure was thus performed for parameters linked to growth kinetics. These parameters were found sensitive in Part I. Nonlinear least-squares algorithms were used from MATLAB Optimization Toolbox ("fmincon" and "fgoalattain" routines), starting with the previous set of parameters (Part I), and minimizing the 

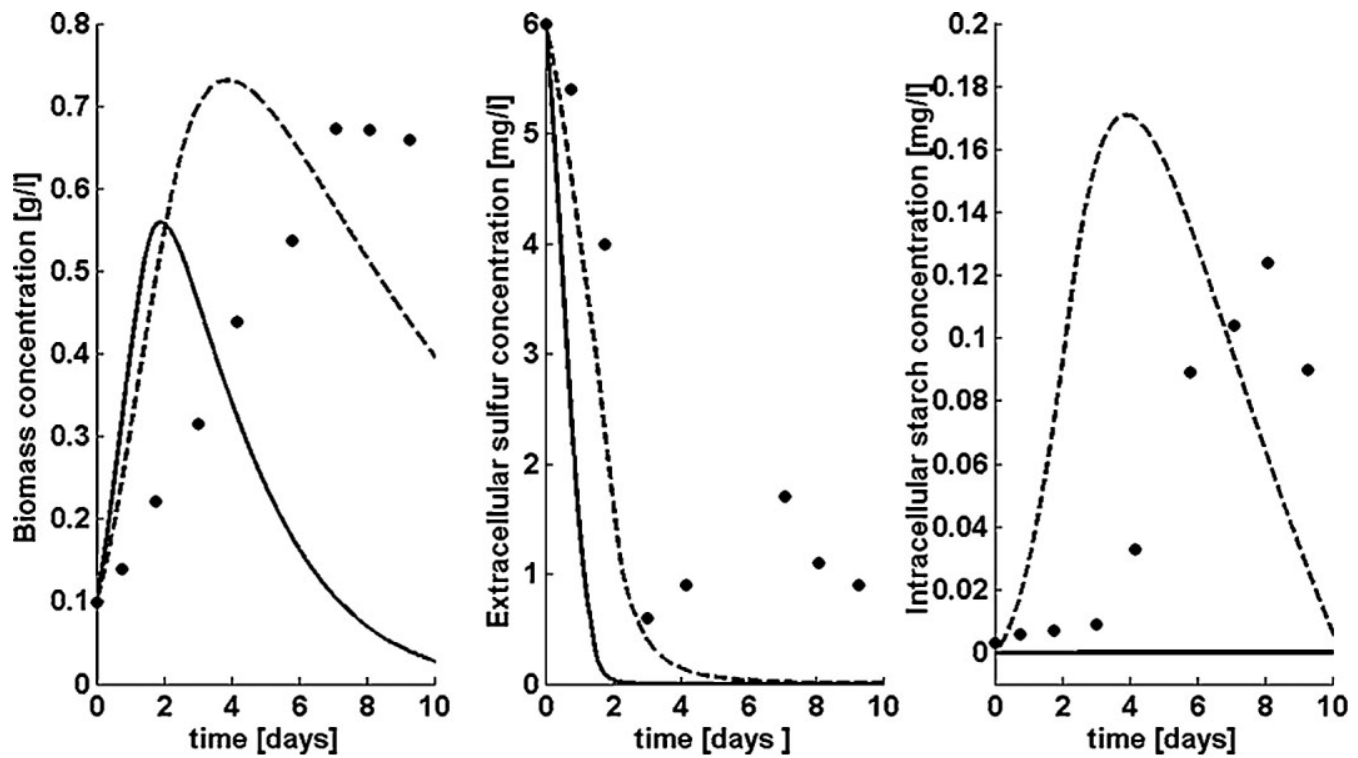

Figure 1. Evolution of biomass, extracellular sulfur, and starch concentrations: comparison between experimental (Batch No. 4, dots) and simulation results: line, using numerical values of the model parameters obtained in dilute conditions (as reported in Part I), dashed-line using re-identified numerical values of $\mu_{\text {max }}$ and $\mu_{\mathrm{s}}$.

following error criterion:

$$
\min \frac{\left(\sum_{i=1}^{N} \frac{\left(y_{\text {model }, i}-y_{\text {exp }, i}\right)^{2}}{\bar{y}_{\text {exp }, i}}\right)}{\sigma^{2}}
$$

where $i$ denotes the sampling, $y_{\text {model }}$ represents the data set given by the model, $y_{\exp }$ is the experimental data set, $\bar{y}_{\exp }$ is the average experimental value, and $\sigma^{2}$ is the standard deviation of the experimental data.

Three batch growths (Batch Nos. 1, 3, and 4) were performed to obtain experimental data necessary for parameter re-identification, and two-batch growth were used for experimental validation (Batch Nos. 2 and 5). The operating conditions for these experiments are reported in Table I:

- Batch Nos. 1, 2, and 3 were run without limiting sulfur concentration, and PFD was varied over a broad range from 110 to $700 \mu \mathrm{molm}^{-2} \mathrm{~s}^{-1}$, to obtain parameters representative of the conditions investigated subsequently in $\mathrm{H}_{2}$-producing experiments.

- Batch Nos. 4 and 5 were conducted in conditions leading to $\mathrm{H}_{2}$ production. Batch No. 4 was performed at a PFD of $110 \mu \mathrm{mol} \mathrm{m}^{-2} \mathrm{~s}^{-1}$ and an initial sulfur concentration of $6 \mathrm{mg} / \mathrm{L}$. Batch No. 5 was designed based on the model analysis (this will be discussed in the next section). It was also used for validation purposes.

\section{Results and Discussion}

\section{Model Validation}

As expected, the optimization procedure conducted on batch growth led to the modification of parameters directly linked to growth, namely $\mu_{\max }$ and $\mu_{\mathrm{s}}\left(\mu_{\max }=0.12 \mathrm{~h}^{-1}\right.$ and $\left.\mu_{\mathrm{s}}=0.0135 \mathrm{~h}^{-1}\right)$. With this new set of parameters, the model correctly described the evolution of the main

Table I. Experimental conditions of Chlamydomonas reinhardtii batch cultivations in PBR.

\begin{tabular}{lccc}
\hline & $\begin{array}{c}\text { Initial biomass } \\
\text { concentration }\left(\mathrm{kg} \mathrm{m}^{-3}\right)\end{array}$ & $\begin{array}{c}\text { Initial extracellular } \\
\text { sulfur concentration }\left(\mathrm{g} \mathrm{m}^{-3}\right)\end{array}$ & $\begin{array}{c}\text { Photon flux density } \\
\left(\mu \mathrm{mol}_{h v} \mathrm{~m}^{-2} \mathrm{~s}^{-1}\right)\end{array}$ \\
\hline Batch No. 1 (photosynthetic growth conditions) & 0.07 & 48 & 110 \\
Batch No. 2 (photosynthetic growth conditions) & 0.18 & Not measured & 300 \\
Batch No. 3 (photosynthetic growth conditions) & 0.5 & 6 & 700 \\
Batch No. 4 (sulfur deprivation) & 0.1 & 22 & 110 \\
Batch No. 5 (sulfur deprivation) & 0.13 & 500 \\
\hline
\end{tabular}

Batches Nos. 1, 2, and 4 were used for identification purposes and Batch Nos. 3 and 5 were used for model validation. 


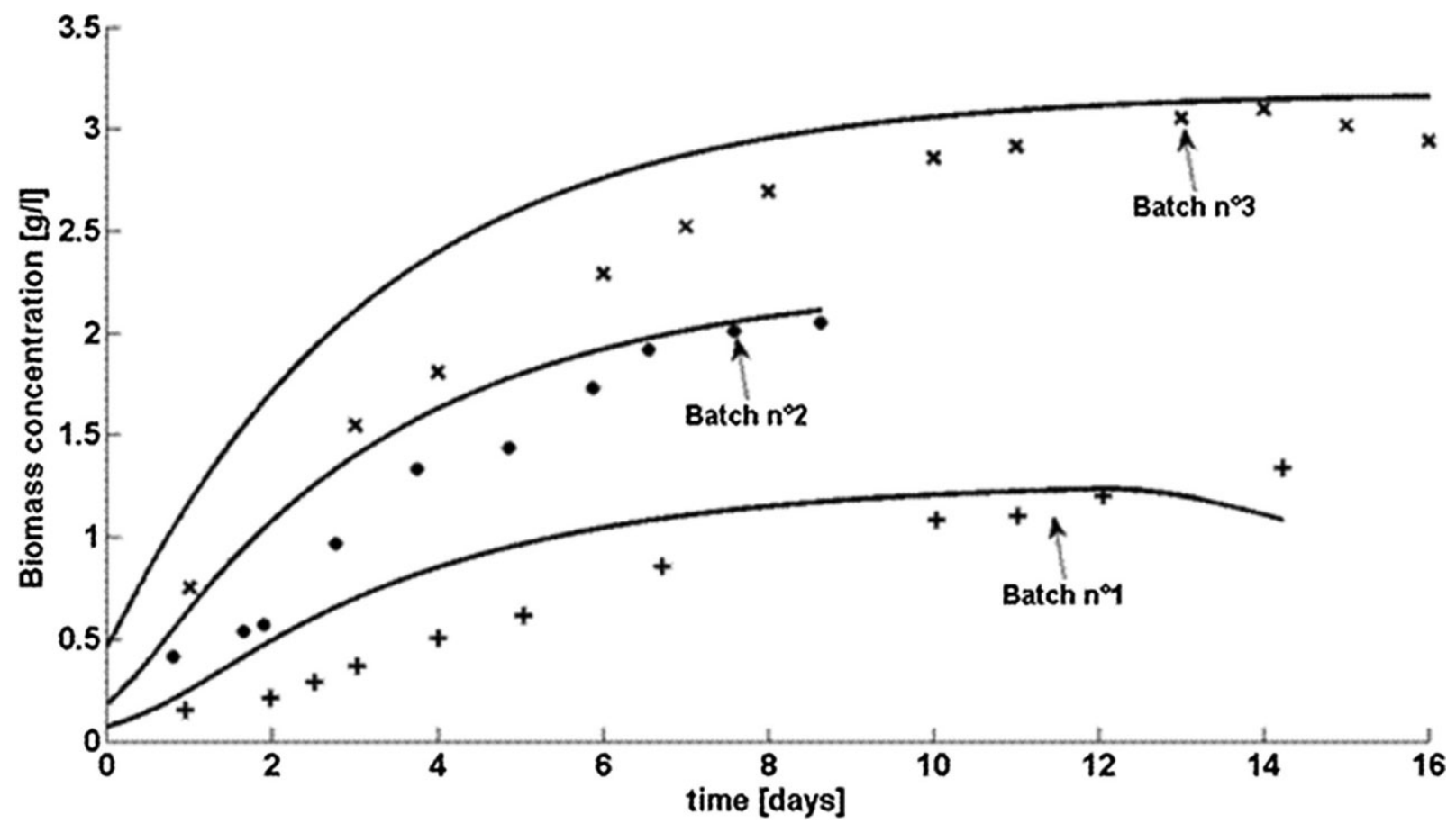

Figure 2. Evolution of biomass concentration in $S$ non-limiting conditions at three different values of incident PFD (110,300, and $\left.700 \mu \mathrm{mol} \mathrm{m}^{-2} \mathrm{~s}^{-1}\right)(B a t c h$ Nos. 1, 2, and 3).

variables measured, that is, biomass, extracellular sulfur, and starch content concentration in non-limiting and Sdeprived conditions (Figs. 2-6). We note that Batch Nos. 2 and 5, not used for calibration, were also accurately represented. Data on starch concentration evolution versus simulated curves are shown in Figure 6. The maximum concentration was well predicted in both batches, but there is still a discrepancy for the kinetics. As the same mathematical expression was used to describe both biomass and starch, the kinetic parameters were identified using only experimental data on biomass. More experimental data will be necessary to improve model performance with respect to the starch accumulation kinetics. Discrepancies were also found in the representation of the sulfur absorption kinetics in non-limiting sulfur conditions, at low PFD and high initial extracellular sulfur concentration. This is shown in Figure 3, where the global sulfur consumption ceased at the end of the batch, at variance with the model prediction. Growth was then full and limited only by light (high biomass concentration without nutrient limitation), indicating that

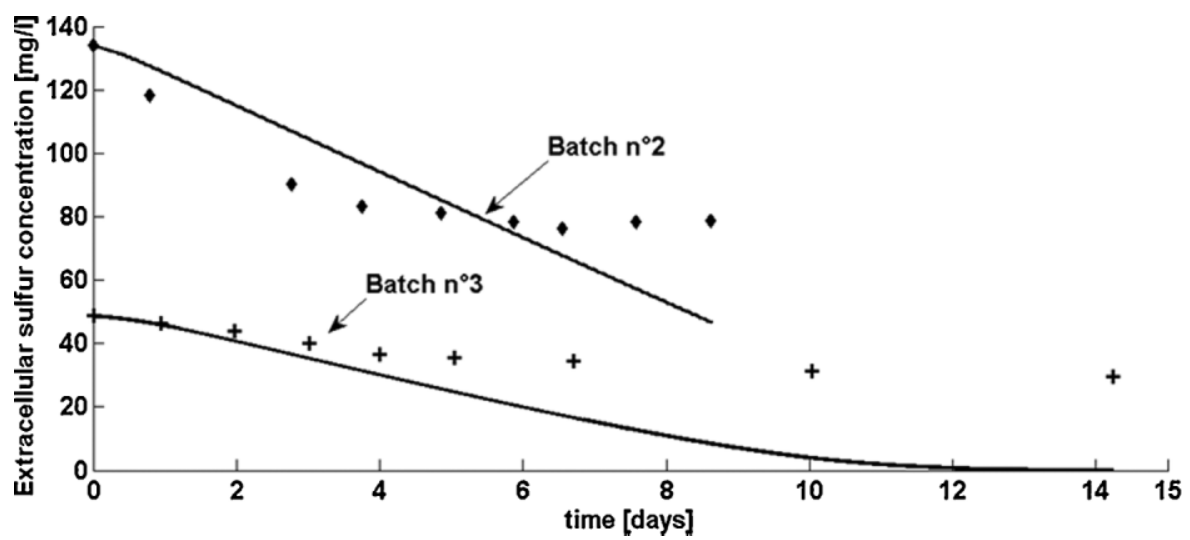

Figure 3. Evolution of extracellular sulfur concentration in $S$ non-limiting conditions at two values of incident PFD (110 and $300 \mu \mathrm{mol}$ photons $\left.\mathrm{m}^{-2} \mathrm{~s}^{-1}\right)$ (Batch Nos. 1 and 2$)$. 


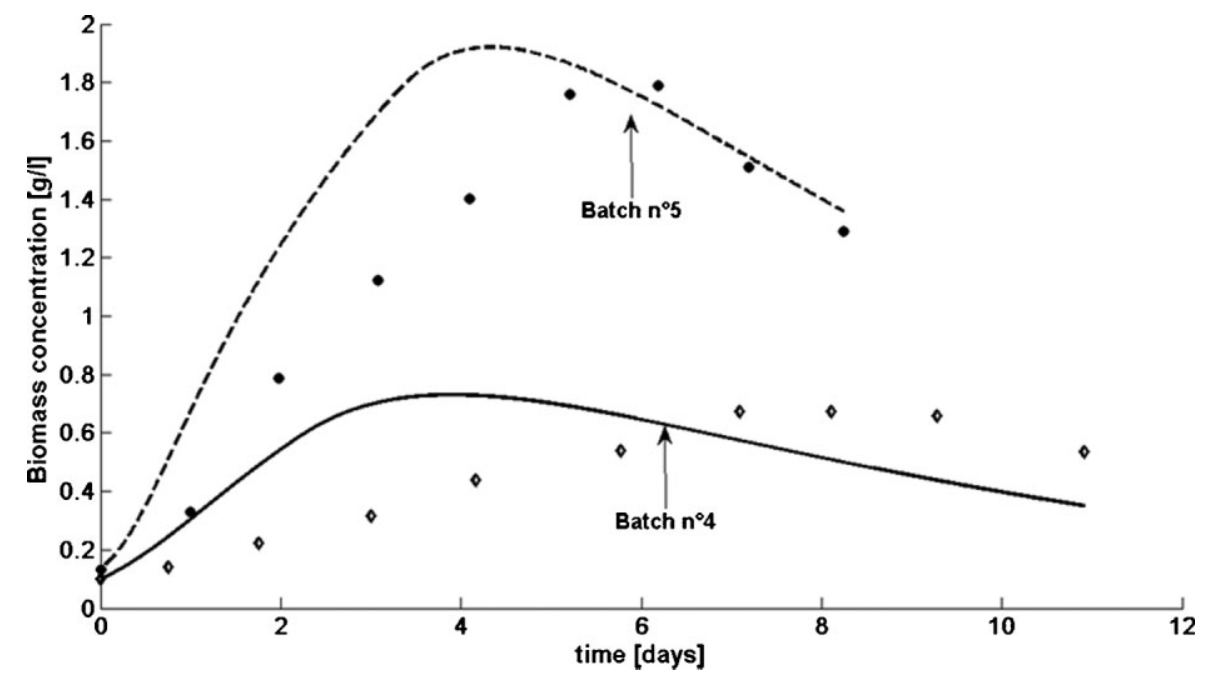

Figure 4. Evolution of biomass concentration in $S$ deprivation conditions at two different values of incident PFD (110 and $500 \mu$ mol photons $\left.\mathrm{m}^{-2} \mathrm{~s}^{-1}\right)$ (Batch Nos. 4 and 5$)$.

the model was not fully adapted for this particular case. These conditions, however, are not representative of $\mathrm{H}_{2}$ production when sulfur deprivation occurs, which was the aim of this study. As illustrated in Figure 5, in these conditions, a close agreement is observed between the experimental and simulated evolution of the extracellular sulfur concentrations (Batch Nos. 4 and 5).

\section{Exploitation of the Model for Determining Cultivation Conditions Leading to $\mathrm{H}_{2}$ Production}

At this point, the model was considered validated for initial sulfur concentrations $\left(S_{0}\right)$ ranging between 6 and $50 \mathrm{mg} / \mathrm{L}$ and PFD $\left(q_{0}\right)$ between 110 and $700 \mu$ mol photons $\mathrm{m}^{-2} \mathrm{~s}^{-1}$, which represents our experimental domain (Table I).

The proposed model was then used in simulation to analyze the evolution of the main state variables within the domain of the experimental operating conditions, with a view to selecting optimal operating conditions in terms of incident PFD $\left(q_{0}\right)$ and initial sulfur concentration $\left(S_{0}\right)$ leading to $\mathrm{H}_{2}$ release. For each simulation, we collected the maximum value of biomass, final internal sulfur quota, and maximum starch concentrations. The results are shown in Figure 7, where surface responses were plotted in the $\left(q_{0}, S\right)$ domain, for an inoculum of $0.07 \mathrm{~kg} \mathrm{~m}^{-3}$ of dry biomass (corresponding to the experimental value used on the set of five batches). Similar shapes were obtained for different

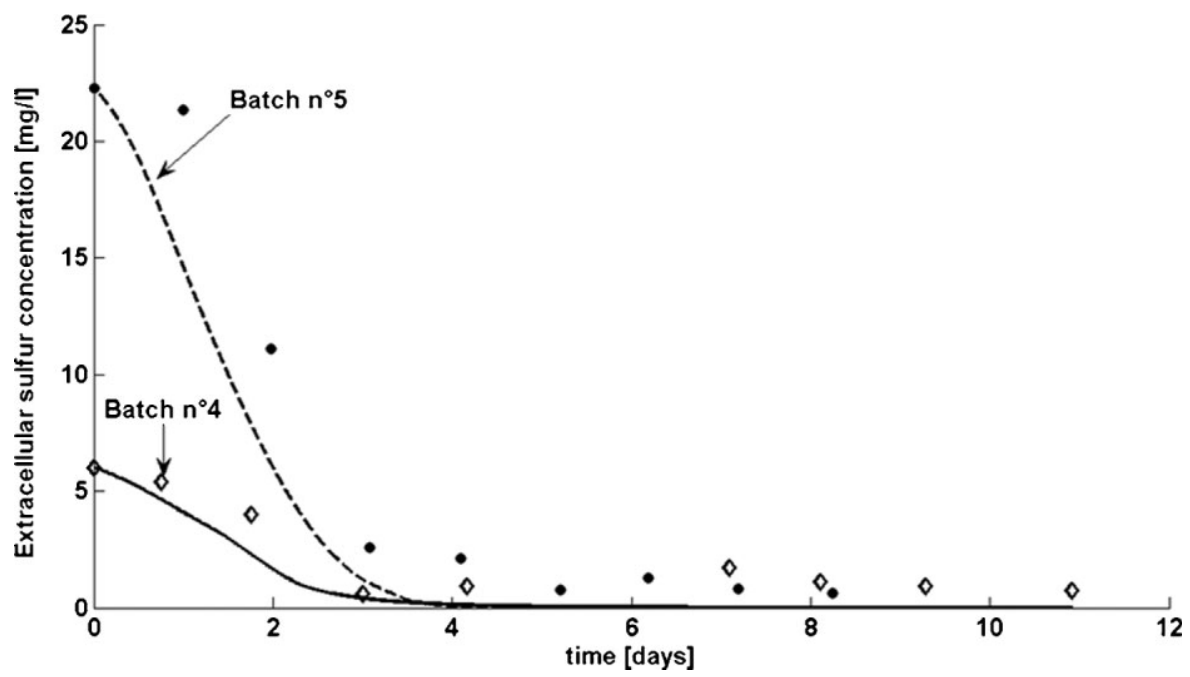

Figure 5. Evolution of extracellular sulfur concentration in $S$ deprivation conditions at two different values of PFD (110 and $500 \mu$ mol photons $\left.\mathrm{m}^{-2} \mathrm{~s}^{-1}\right)(B a t c h$ Nos. 4 and 5$)$. 


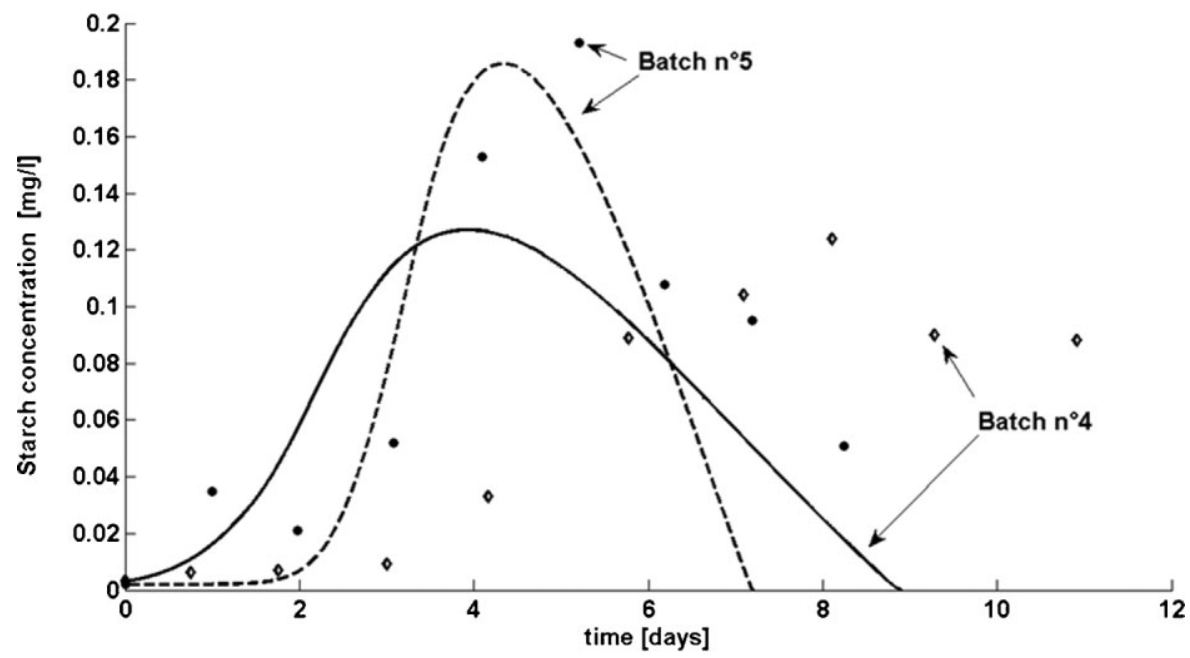

Figure 6. Evolution of extracellular and intracellular starch concentration in $S$ deprivation conditions at two different values of PFD $\left(110\right.$ and $500 \mu \mathrm{mol}$ photons $\left.\mathrm{m}^{-2} \mathrm{~s}^{-1}\right)$ (Batch Nos. 4 and 5).

values of inoculum concentration between 0.05 and $1 \mathrm{~kg} / \mathrm{m}^{3}$ (data not shown). Surface responses exhibited the influence of operating conditions on the maximal biomass concentration that could be reached in the explored operating domain. To obtain a high biomass concentration with a maximum internal sulfur quota at the time the starvation occurs, and a maximum starch accumulation, simulation results suggest a high initial sulfur concentrations and incident light flux. Experimental results of batch cultivations Nos. 4 and 5 were added to the surface responses. Experimental and simulated data were found to be in agreement.

\section{Experimental Investigation of $\mathrm{H}_{2}$ Production With Optimized Operating Conditions}

Based on model analysis, experimental conditions for Batch No. 5 were selected for the validation, that is, a PFD of $500 \mu \mathrm{mol}$ photons $\mathrm{m}^{-2} \mathrm{~s}^{-1}$ and an initial sulfur concentration of $22 \mathrm{mg} / \mathrm{L}$. The inoculum concentration was $0.1 \mathrm{~kg} \mathrm{~m}^{-3}$.

In these conditions, biomass concentration increased during the first 5 days to reach a value of $1.8 \mathrm{~kg} \mathrm{~m}^{-3}$ (Fig. 3). Concomitant to this biomass production, extracellular sulfur was consumed, falling to a concentration close to zero after 4 days of culture. The sulfur starvation led to starch accumulation with a maximal concentration of $0.19 \mathrm{~kg} \mathrm{~m}^{-3}$ obtained at day 6 (Fig. 6). Time separation of oxygen and hydrogen production during the experiment was perfectly illustrated here (Fig. 8). The maximum volumetric oxygen productivity $\left(26 \mathrm{~mL} \mathrm{O}_{2} / \mathrm{h} / \mathrm{L}\right.$ of culture) was obtained when the PBR was fully illuminated, but without a dark zone, leading to the "luminostat regime" $(\gamma=1 \pm 15 \%$, see Takache et al., 2010 for a complete explanation). This volumetric productivity decreased when a dark zone appeared in the PBR, coupled with a decrease in the photosynthetic capacities due to the onset of sulfur deprivation (data not represented in figures). Anoxic conditions were progressively set up, leading to hydrogen production with a maximum hydrogen volumetric productivity of $3.1 \pm 0.4 \mathrm{~mL} \mathrm{H}_{2} / \mathrm{h} / \mathrm{L}$ of culture (or $77.5 \pm$ $10 \mathrm{~mL} \mathrm{H}_{2} / \mathrm{m}^{2} \mathrm{~h}$ or $1.8 \pm 0.3 \mathrm{~mL} \mathrm{H}_{2} / \mathrm{h} / \mathrm{g}$ of biomass dry weight).

As already observed in Degrenne et al. (2010b), radiative transfer conditions (as represented here by the $\gamma$ value) are important to control, especially in the case of autotrophic conditions. A rigorous control of radiative transfer conditions can allow $\mathrm{H}_{2}$ production in such conditions, and it was shown that without deprivation, a value below 0.25 was necessary to set up anoxic conditions. This influence was combined here with the effect of sulfur deprivation on the decrease in photosynthetic capacity. As a consequence, anoxia was reached when $\gamma=0.71 \pm 0.11$ in Batch No. 4 and $\gamma=0.49 \pm 0.07$ in Batch No. 5. We note that in both cases, all the photon flux was absorbed.

The different experiments leading to $\mathrm{H}_{2}$ production can be compared. Although the optimization procedure led to an increase in the volumetric and areal $\mathrm{H}_{2}$ productivity (conducted here in autotrophic conditions), we note that the maximum specific hydrogen productivity remained nearly constant and was around $2 \mathrm{~mL} \mathrm{H}_{2} / \mathrm{h} / \mathrm{g}$ of biomass, even using a broad range of initial conditions of biomass dry weight and sulfur concentrations (Fig. 8, Table II). This clearly indicates a biological limitation. Hydrogen productivity was increased here, but by reaching higher biomass concentration when using higher PFD, as allowed when working with PBRs.

To complete this analysis, it is useful to express results in terms of yields. These yields can be defined as follows (terms 

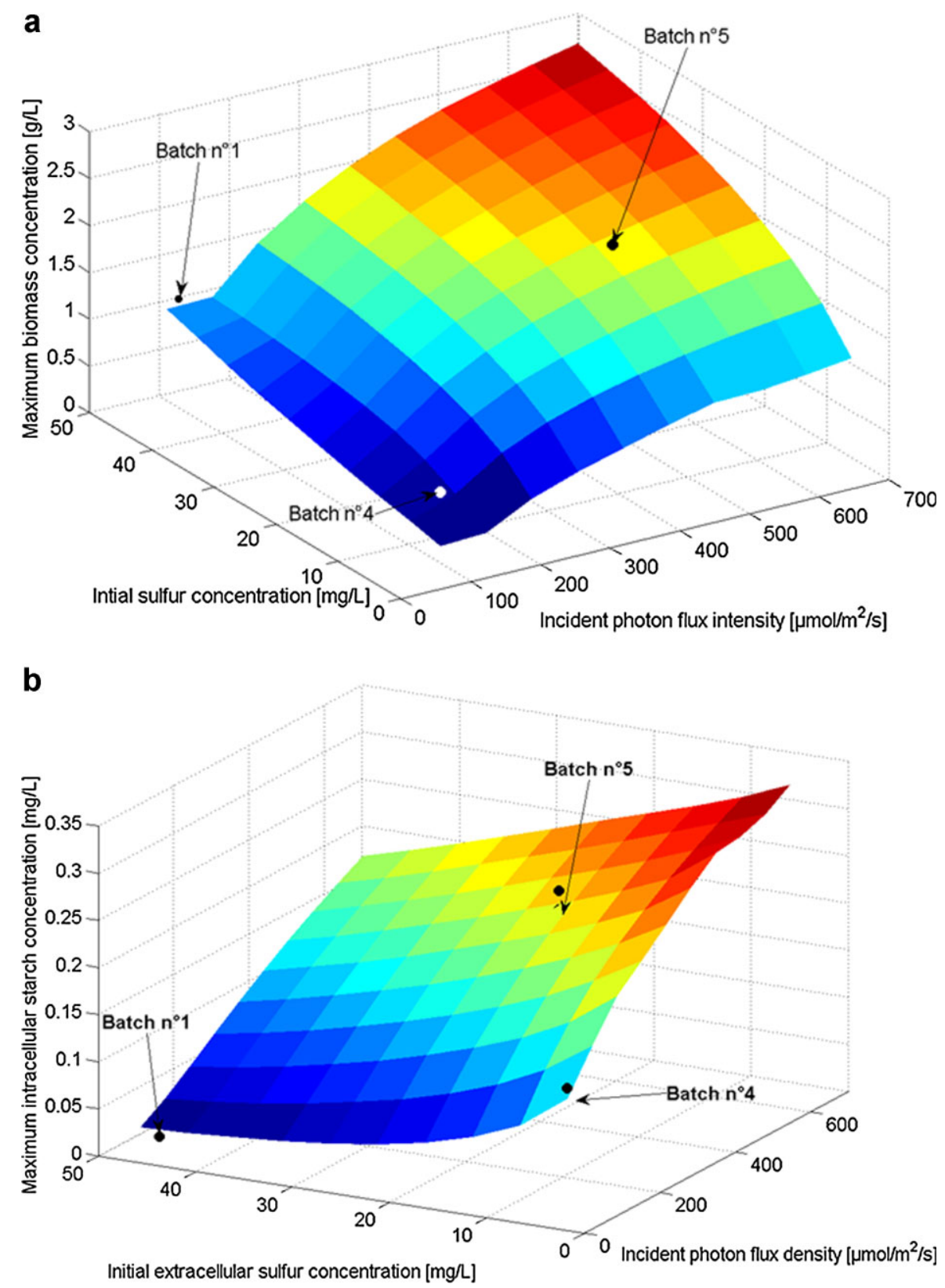

Figure 7. Surface responses representing the effect of PFD and initial extracellular concentrations on the maximum biomass concentration (a) and the maximum starch concentration (b) achieved during the sulfur deprivation protocol. Values of experiments are reported. [Color figure can be seen in the online version of this article, available at http://wileyonlinelibrary.com/bit]

are defined in the nomenclature with their corresponding units and values):

$$
\begin{gathered}
\text { YIELD1 }=\frac{\int_{t_{1}}^{t_{3}} r_{\mathrm{H}_{2}}(t) \rho_{\mathrm{H}_{2}} \Delta G\left(\mathrm{H}_{2}\right) \mathrm{d} t+\left(\Delta G\left(x_{3}\right)-\Delta G\left(x_{1}\right)\right)}{\operatorname{PFD}\left(t_{3}-t_{1}\right) S_{\mathrm{PBR}}} \\
\text { YIELD2 }=\frac{\int_{t_{2}}^{t_{3}} r_{\mathrm{H}_{2}}(t) \rho_{\mathrm{H}_{2}} \Delta G\left(\mathrm{H}_{2}\right) \mathrm{d} t}{\operatorname{PFD}\left(t_{3}-t_{2}\right) S_{\mathrm{PBR}}+\left(\Delta G\left(x_{2}\right)-\Delta G\left(x_{3}\right)\right)}
\end{gathered}
$$

In autotrophic conditions, light is the only energy source that is converted by photosynthesis into biomass and hydrogen. This is represented by YIELD 1, which gives the energy yield of conversion of light into hydrogen and biomass calculated over the total production cycle (from the beginning, $t_{1}$, to the end, $t_{3}$, of culture). Because hydrogen production is a two-step process, it is also useful to introduce a specific yield for the hydrogen production phase. Hydrogen is then the result of light received and biomass catabolism. In a first instance, it can be represented by YIELD 2, which is the energy yield 


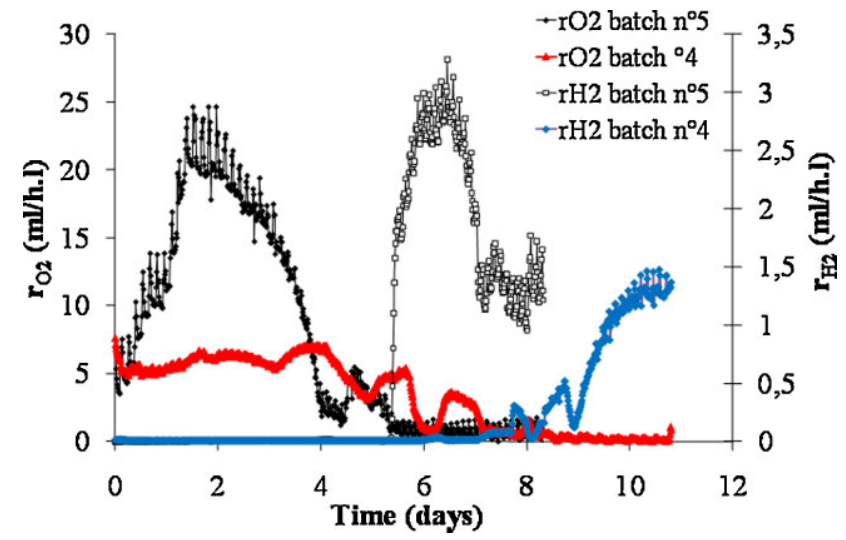

Figure 8. Time course of oxygen and hydrogen gas production during Batch Nos. 4 and 5. The progressive sulfur deprivation led in both cases to oxygen production representing the biomass production and potential starch accumulation when sulfur deprivation occurred. When biomass concentration was sufficiently high (forming a dark zone in the PBR) and effect of sulfur deprivation on photosynthetic capacities (decrease in maximal quantum yield efficiency), anaerobic conditions under light appeared, leading to a sustained hydrogen production in autotrophic conditions. [Color figure can be seen in the online version of this article, available at http://wileyonlinelibrary.com/bit]

of conversion of light and biomass degradation into hydrogen.

Yields obtained in both batches leading to hydrogen production are given in Table II, with a detailed explanation for different phases in Figure 9. Assuming a mass energy value of the biomass of $30 \mathrm{~kJ} / \mathrm{g}$ of biomass, $1.85 \%$ of the light received $(2,480 \mathrm{~kJ})$ was converted into biomass. In terms of hydrogen ( $194 \mathrm{~mL}$ produced, $16 \mathrm{mg}$ of hydrogen gas, $1.9 \mathrm{~kJ}$ of hydrogen gas), the yield was $0.1 \%$ (YIELD 1 ). Considering only the hydrogen production phase, light $(880 \mathrm{~kJ})$, and catabolism of biomass $(21 \mathrm{~kJ})$ energies were converted into hydrogen with a yield of $0.2 \%$ (YIELD 2). We note that $9 \%$ of the energy resulting from biomass catabolism led to hydrogen production. For information, a yield of $1 \%$ was roughly obtained in the hydrogen production phase by Giannelli et al. (2009) in the more classical case of photoheterotrophic conditions (but acetate added in the medium acted here as an additional source of energy). These results could also be compared to classical values of yield of light conversion into biomass (photosynthetic yield), which are usually in the range 515\% (Cornet, 2009).

Although calculations are only a first estimate, experimental results emphasize that the energy yield of $\mathrm{H}_{2}$ production with algae is low, and several bottlenecks have still to be overcome, at both biological and process levels. At the PBR level, a more detailed energy analysis should be used in future work. As shown in this work, the stoichiometry and kinetics of the reactions were accurately represented (starch accumulation, sulfur deprivation). Adding energy modeling of the process could allow its systematic optimization in this regard.

\section{Concluding Remarks}

A modeling approach was used to determine operating conditions allowing hydrogen gas to be produced in a PBR with green microalgae, using the sulfur deprivation protocol. The mechanistic model proposed in Part I of this work was validated here with autotrophic production.

Simulations allowed, in particular, favorable conditions to be set for a broad range of PFD values from 110 to $500 \mu \mathrm{mol}$ photons $\mathrm{m}^{-2} \mathrm{~s}^{-1}$, with a high biomass concentration reached just before sulfur deprivation. It led to an increase in hydrogen volumetric productivity, but also to a high light attenuation in the culture bulk, favoring anoxia establishment in combination with the sulfur deprivation effect on the photosynthetic activity decrease. The methodology used here thus completes the protocol of sulfur deprivation (Melis et al., 2000) by adding a rigorous control of light attenuation in the PBR, allowing further optimization by enabling, for example, work at high PFD to obtain high biomass concentration during the $\mathrm{H}_{2}$ production phase.

Despite the systematic optimization applied, hydrogen production expressed per gram of biomass (specific hydrogen production) was found to be nearly constant, whatever the conditions tested. This clearly indicates a biological limitation in the $\mathrm{H}_{2}$-producing metabolism. It thus encourages us to pursue the research effort on the optimization of strains and bioenergy pathways. Productivities and yields are still low. It was shown, for example, that only $0.2 \%$ of the total energy used (PFD and biomass degradation) was recovered in the hydrogen

Table II. Yields of hydrogen production in autotrophic conditions.

\begin{tabular}{|c|c|c|c|c|c|c|}
\hline PFD & $\begin{array}{l}\text { Total hydrogen } \\
\text { production }(\mathrm{mL})\end{array}$ & $\begin{array}{c}\text { Duration of } \mathrm{H}_{2} \\
\text { production phase }(\mathrm{h})\end{array}$ & $\begin{array}{l}\text { Maximum } \mathrm{H}_{2} \\
\text { production rate }\end{array}$ & $\begin{array}{c}\text { Yield } 2 \\
\text { (hydrogen production } \\
\text { phase), } \%\end{array}$ & $\begin{array}{c}\text { Yield } 2 \\
\text { (maximal hydrogen } \\
\text { production rate), \% }\end{array}$ & $\begin{array}{c}\text { Yield } 1 \\
\text { (global cycle), } \\
\%\end{array}$ \\
\hline 110 & 56 & 86 & $\begin{array}{l}1.9 \pm 0.4 \mathrm{~mL} \mathrm{H}_{2} / \mathrm{gh} \\
1.1 \pm 0.2 \mathrm{~mL} \mathrm{H}_{2} / \mathrm{h} \mathrm{L} \\
25 \pm 5 \mathrm{~mL} \mathrm{H}_{2} / \mathrm{m}^{2} \mathrm{~h}\end{array}$ & 0.2 & 0.55 & 0.1 \\
\hline 500 & 195 & 71 & $\begin{array}{c}1.8 \pm 0.4 \mathrm{~mL} \mathrm{H}_{2} / \mathrm{gh} \\
3.1 \pm 0.4 \mathrm{~mL} \mathrm{H}_{2} / \mathrm{h} \mathrm{L} \\
77.5 \pm 10 \mathrm{~mL} \mathrm{H}_{2} / \mathrm{m}^{2} \mathrm{~L}\end{array}$ & 0.2 & 0.40 & 0.1 \\
\hline
\end{tabular}




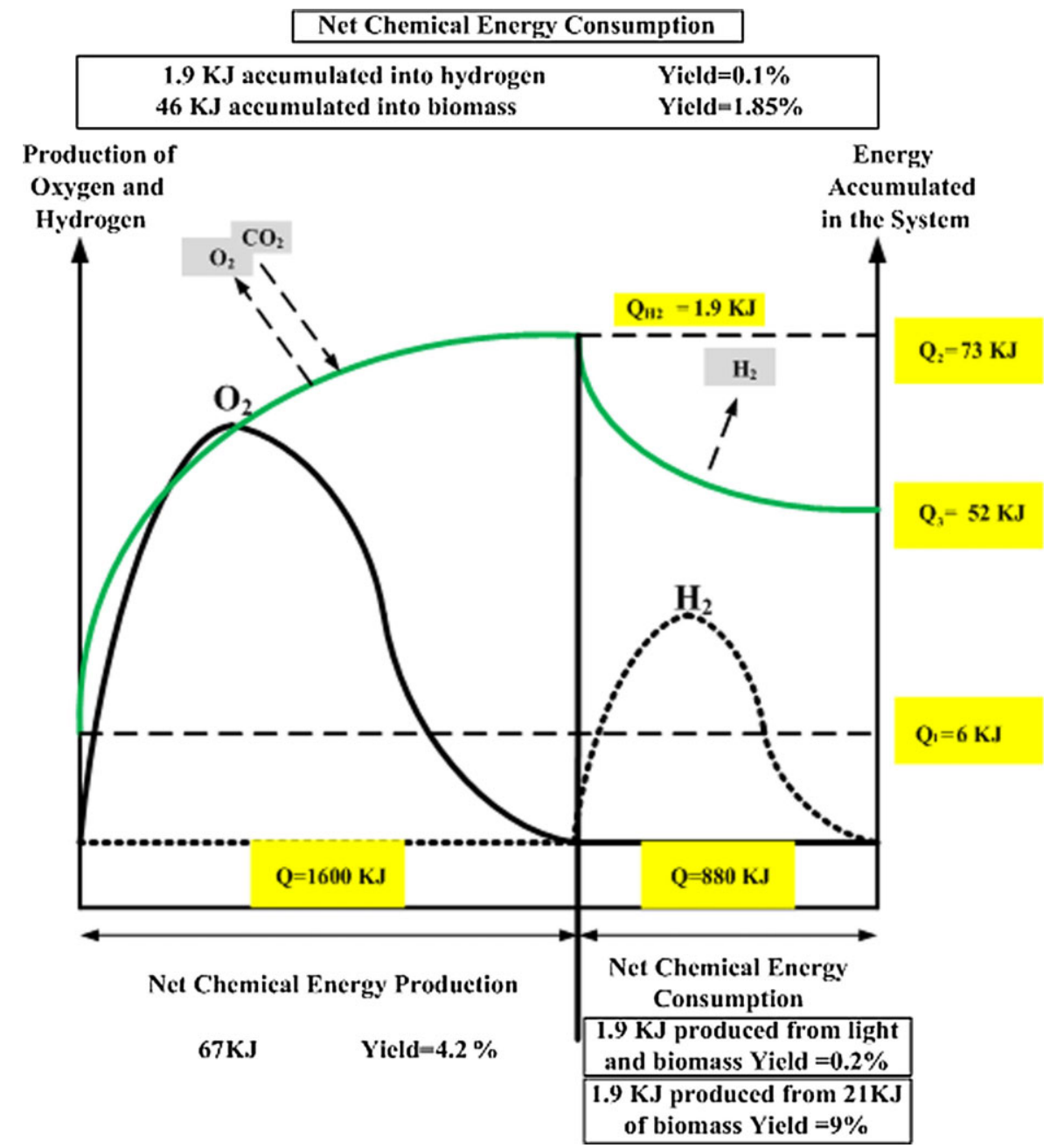

Figure 9. Global energy yield for hydrogen production in autotrophic conditions and under continuous light exposure. The protocol was optimized in terms of maximum biomass concentration reached. [Color figure can be seen in the online version of this article, available at http://wileyonlinelibrary.com/bit]

production phase. Assuming that $1 \mathrm{~g}$ of dry biomass contains a calorific capacity of about $30 \mathrm{~kJ} / \mathrm{g}$, only $9 \%$ of the energy contained in the biomass is thus transformed into hydrogen. To understand this value better, a detailed analysis of metabolic fluxes leading to hydrogen gas production will be of interest, as well as an energy analysis of these fluxes using thermodynamic tools. Work on this is in progress in our laboratory.

Further studies will also aim at using the model to optimize the sulfur deprivation protocol. Special attention will be paid to the energy yield of the global cycle of production. In this study, only constant PFD values were applied. A dynamic control could thus be considered to investigate its effect on hydrogen production and optimize the yield of production by delivering appropriate PFD for each producing phase (biomass, starch, and hydrogen). The model will also be extended to the $\mathrm{H}_{2}$-producing phase, especially by simulating PSII-dependent and -independent pathways. Finally, we note that the model, applied here for a wild-type strain, can be simply adapted to other optimized strains. Specific optimization such as small antennae or genetic modification of cell metabolism (e.g., to promote starch over-accumulation) can be simulated by determining corresponding new parameters (optical properties and kinetic parameters). This will be also the aim of further specific work.

Part of this work has been founded by "PhotobioH2" and "AlgoH2" ANR Program (French National Program), and by the European FP7Program "SolarH2".

\section{Nomenclature}
$a_{\text {light }}$ illuminated specific area of the PBR $\left(\mathrm{m}^{2} / \mathrm{m}^{3}\right)$
$D \quad$ dilution rate $\left(\mathrm{h}^{-1}\right)$
$f(Q) \quad$ inhibition of the photosynthetic activity
$G \quad$ irradiance $\left(\mathrm{mol}_{h v} \mathrm{~m}^{-2} \mathrm{~s}^{-1}\right)$
$K_{\mathrm{I}} \quad$ half saturation constant of growth $\left(\mathrm{mol}_{h v} \mathrm{~m}^{-2} \mathrm{~s}^{-1}\right)$ 
$K_{\mathrm{II}} \quad$ inhibition constant of growth kinetics $\left(\mathrm{mol}_{h \nu} \mathrm{m}^{-2} \mathrm{~s}^{-1}\right)$

$L \quad$ PBR depth (m)

Q intracellular sulfur quota $\left(\mathrm{g} \mathrm{S} \mathrm{g} \mathrm{biomass}^{-1}\right)$

PFD photon flux density $\left(\mathrm{mol}_{h v} \mathrm{~m}^{-2} \mathrm{~s}^{-1}\right)$

$r_{\mathrm{H}_{2}} \quad$ rate of hydrogen production $(\mathrm{mL} / \mathrm{min})$

$r_{X_{\mathrm{p}}} \quad$ photosynthetic growth volumetric rate $\left(\mathrm{gXL}^{-1} \mathrm{~h}^{-1}\right)$

$r_{X_{S}} \quad$ respiratory volumetric rate $\left(\mathrm{gXL}^{-1} \mathrm{~h}^{-1}\right)$

$S \quad$ substrate concentration $\left(\mathrm{g} \mathrm{L}^{-1}\right)$

$S_{\mathrm{i}} \quad$ initial substrate concentration $\left(\mathrm{g} \mathrm{L}^{-1}\right)$

$t \quad$ time (days)

$t_{1} \quad$ time at the start of the experiment (days)

$t_{2}$ time at the start of the hydrogen production phase (days)

$t_{3}$ time at the end of the hydrogen production phase (days)

$X \quad$ biomass concentration $\left(\mathrm{g} \mathrm{L}^{-1}\right)$

$x_{1} \quad$ biomass at the start of the experiment $(\mathrm{g})$

$x_{2} \quad$ biomass at the start of the hydrogen production phase $(\mathrm{g})$

$x_{3} \quad$ biomass at the end of the hydrogen production phase $(\mathrm{g})$

$X_{\mathrm{c}} \quad$ intracellular starch concentration $\left(\mathrm{g} \mathrm{L}^{-1}\right)$

\section{Greek Letters}

$\Delta G\left(\mathrm{H}_{2}\right)$ free enthalpy of hydrogen combustion $(120 \mathrm{~kJ} / \mathrm{g})$

$\Delta G(X) \quad$ free enthalpy of biomass combustion (estimated at $30 \mathrm{~kJ} / \mathrm{g}$ )

$\gamma \quad$ volumetric illuminated fraction of the PBR

$\rho_{\mathrm{H}_{2}} \quad$ hydrogen density $\left(P=1 \mathrm{~atm}\right.$ and $\left.25^{\circ} \mathrm{C} ; 0.082 \mathrm{~kg} \mathrm{~m}^{-3}\right)$

$\mu \quad$ specific growth rate $\left(\mathrm{h}^{-1}\right)$

$\mu \quad$ specific growth rate for a non-limiting quota $Q\left(\mathrm{~h}^{-1}\right)$

$\mu_{\max } \quad$ maximal specific growth rate $\left(\mathrm{h}^{-1}\right)$

$\mu_{\mathrm{p}} \quad$ photosynthetic growth rate $\left(\mathrm{h}^{-1}\right)$

$\mu_{\mathrm{s}} \quad$ respiration rate $\left(\mathrm{h}^{-1}\right)$

\section{References}

Benemann JR, Berenson JA, Kaplan NO, Kamen MD. 1973. Hydrogen evolution by a chloroplast-ferredoxin-hydrogenase system. Proc Natl Acad Sci USA 70(8):2317-2320.

Cornet J-F. 2009. Calculation of optimal design and ideal productivities of volumetrically lightened photobioreactors using the constructal approach. Chem Eng Sci 65(2):985-998.

Degrenne B, Pruvost J, Christophe G, Cornet JF, Cogne G, Legrand J. 2010. Investigation of the combined effects of acetate and photobioreactor illuminated fraction in the induction of anoxia for hydrogen production by Chlamydomonas reinhardtii. Int J Hydrogen Energy 35(19): 10741-10749.

Degrenne B, Pruvost J, Legrand J. 2011. Effect of prolonged hypoxia in autotrophic conditions in the hydrogen production by the green microalga Chlamydomonas reinhardtii in photobioreactor. Bioresource Technol 102:1035-1043.

Fedorov AS, Kosourov S, Ghirardi ML, Seibert M. 2005. Continuous hydrogen photoproduction by Chlamydomonas reinhardtii. Appl Biochem Biotechnol 121:403-412.

Fouchard S, Hemschemeier A, Caruana A, Pruvost J, Legrand J, Happe T, Peltier G, Cournac L. 2005. Autotrophic and mixotrophic hydrogen photoproduction in sulfur-deprived Chlamydomonas cells. Appl Environ Microbiol 71(10):6199-6205.

Fouchard S, Pruvost J, Degrenne B, Legrand J. 2008. Investigation of $\mathrm{H}_{2}$ production using the green microalga Chlamydomonas reinhardtii in a fully-controlled photobioreactor fitted with on-line gas analysis. Int J Hydrogen Energy 33(13):3302-3310.
Fouchard S, Pruvost J, Degrenne B, Titica M, Legrand J. 2009. Kinetic modeling of light limitation and sulfur deprivation effects in the induction of hydrogen production with Chlamydomonas reinhardtii: Part I. Model development and parameter identification. Biotechnol Bioeng 102:232-245.

Gaffron H, Rubin J. 1942. Fermentative and photochemical production of hydrogen in algae. J Gen Physiol 26(2):219-240.

Ghirardi ML, Togasaki RK, Seibert M. 1997. Oxygen sensitivity of algal $\mathrm{H}_{2}$ production. Appl Biochem Biotechnol 63(5):141-151.

Ghirardi ML, Kosourov S, Seibert M. 2000. Cyclic photobiological algal $\mathrm{H}_{2}$ production. NREL/CP-570-30535.

Giannelli L, Scoma A, Torzillo G. 2009. Interplay between light intensity, chlorophyll concentration and culture mixing on the hydrogen production in sulfur-deprived Chlamydomonas reinhardtii cultures grown in laboratory photobioreactors. Biotechnol Bioeng 104(1):76-90.

Guo Z, Chen Z, Zhang W, Yu X, Jin M. 2008. Improved hydrogen photoproduction regulated by carbonylcyanide $m$-chlorophenylhydrazone from marine green alga Platymonas subcordiformis grown in $\mathrm{CO}_{2}$ supplemented air bubble column bioreactor. Biotechnol Lett 30(5): 877-883.

Harris, EH. 1989. The Chlamydomonas sourcebook. A comprehensive guide to biology and laboratory use. SD, New York: Academic Press Inc.

Kim JP, Kim K-R, Choi SP, Han SJ, Kim MS, Sim SJ. 2010. Repeated production of hydrogen by sulfate re-addition in sulfur deprived culture of Chlamydomonas reinhardtii. Hydrogen J Hydrogen Energy 35(24):13387-13397.

Klein U, Betz A. 1978. Fermentative metabolism of hydrogen-evolving Chlamydomonas moewusii. Plant Physiol 61(6):953-956.

Kosourov S, Tsygankov A, Seibert M, Ghirardi ML. 2002. Sustained hydrogen photoproduction by Chlamydomonas reinhardtii: Effects of culture parameters. Biotechnol Bioeng 78(7):731-740.

Kosourov S, Makarova V, Fedorov AS, Tsygankov A, Seibert M, Ghirardi ML. 2005. The effect of sulfur re-addition on $\mathrm{H}_{2}$ photoproduction by sulfur-deprived green algae. Photosynth Res 85(3):295-305.

Kosourov S, Patrusheva E, Ghirardi ML, Seibert M, Tsygankov A. 2007. A comparison of hydrogen photoproduction by sulfur-deprived Chlamydomonas reinhardtii under different growth conditions. J Biotechnol 128(4):776-787.

Laurinavichene TV, Tolstygina IV, Galiulina RR, Ghirardi ML, Seibert M, Tsygankov AA. 2002. Dilution methods to deprive Chlamydomonas reinhardtii cultures of sulfur for subsequent hydrogen photoproduction. Int J Hydrogen Energy 27(11-12):1245-1249.

Laurinavichene T, Fedorov A, Ghirardi M-L, Seibert M, Tsygankov A. 2006. Demonstration of sustained hydrogen photoproduction by immobilized, sulfur-deprived Chlamydomonas reinhardtii cells. Int J Hydrogen Energy 31(5):659-667.

Laurinavichene TV, Kosourov SN, Ghirardi ML, Seibert M, Tsygankov AA. 2008. Prolongation of $\mathrm{H} 2$ photoproduction by immobilized, sulfurlimited Chlamydomonas reinhardtii cultures. J Biotechnol 134(3-4): 275-277.

Melis A. 2002. Green alga hydrogen production: Progress, challenges and prospects. Int J Hydrogen Energy 27(11-12):1217-1228.

Melis A, Zhang LP, Forestier M, Ghirardi ML, Seibert M. 2000. Sustained photobiological hydrogen gas production upon reversible inactivation of oxygen evolution in the green alga Chlamydomonas reinhardtii. Plant Physiol 122(1):127-136.

Takache H, Christophe G, Cornet J-F, Pruvost J. 2010. Experimental and theoretical assessment of maximum productivities for the microalgae Chlamydomonas reinhardtii in two different geometries of photobioreactors. Biotechnol Prog 26(2):431-440.

Tsygankov A, Kosourov S, Tolstygina I, Ghirardi ML, Seibert M. 2006. Hydrogen production by sulfur-deprived Chlamydomonas reinhardtii under photoautotrophic conditions. Int J Hydrogen Energy 31(Sp Iss SI):1574-1584.

Zhang LP, Happe T, Melis A. 2002. Biochemical and morphological characterization of sulfur-deprived and $\mathrm{H}_{2}$-producing Chlamydomonas reinhardtii (green alga). Planta 214(4):552-561. 